Article

\title{
Region-Specific Sialylation Pattern of Prion Strains Provides Novel Insight into Prion Neurotropism
}

\author{
Natallia Makarava ${ }^{1,2}$, Jennifer Chen-Yu Chang ${ }^{1,2}$ and Ilia V. Baskakov 1,2,* \\ 1 Center for Biomedical Engineering and Technology, University of Maryland School of Medicine, Baltimore, \\ MD 21201, USA; nmakarava@som.umaryland.edu (N.M.); cchang1@som.umaryland.edu (J.C.-Y.C.) \\ 2 Department of Anatomy and Neurobiology, University of Maryland School of Medicine, Baltimore, \\ MD, 21201, USA \\ * Correspondence: Baskakov@som.umaryland.edu
}

Received: 18 December 2019; Accepted: 23 January 2020; Published: 28 January 2020

\begin{abstract}
Mammalian prions are unconventional infectious agents that invade and replicate in an organism by recruiting a normal form of a prion protein $\left(\mathrm{PrP}^{\mathrm{C}}\right)$ and converting it into misfolded, disease-associated state referred to as $\mathrm{PrP}^{\mathrm{Sc}}$. $\mathrm{PrP}^{\mathrm{C}}$ is posttranslationally modified with two N-linked glycans. Prion strains replicate by selecting substrates from a large pool of $\mathrm{PrP}^{\mathrm{C}}$ sialoglycoforms expressed by a host. Brain regions have different vulnerability to prion infection, however, molecular mechanisms underlying selective vulnerability is not well understood. Toward addressing this question, the current study looked into a possibility that sialylation of $\mathrm{PrP}^{\mathrm{Sc}}$ might be involved in defining selective vulnerability of brain regions. The current work found that in 22L -infected animals, $\mathrm{PrPS}^{\mathrm{Sc}}$ is indeed sialylated in a region dependent manner. $\mathrm{PrP}^{\mathrm{Sc}}$ in hippocampus and cortex was more sialylated than $\mathrm{PrP}^{\mathrm{Sc}}$ from thalamus and stem. Similar trends were also observed in brain materials from RML- and ME7-infected animals. The current study established that $\mathrm{PrP}^{\mathrm{Sc}}$ sialylation status is indeed region-specific. Together with previous studies demonstrating that low sialylation status accelerates prion replication, this work suggests that high vulnerability of certain brain region to prion infection could be attributed to their low sialylation status.
\end{abstract}

Keywords: prions; prion disease; N-linked glycans; sialic acid; sialylation; prion strains; thalamus; two-dimensional gel electrophoresis

\section{Introduction}

Mammalian prions are unconventional infectious agents that consist of misfolded, self-replicating states of a sialoglycoprotein called the prion protein or $\operatorname{PrP}^{\mathrm{C}}$ [1,2]. Prions replicate by recruiting and converting $\mathrm{PrPC}^{\mathrm{C}}$ molecules expressed by a host into misfolded, self-replicating states referred to as $\mathrm{PrP}^{\mathrm{Sc}}[3,4]$. While prions are unconventional pathogens, they spread from cell to cell in CNS and elicit neuroinflammatory response that resembles the response of CNS to viral infections [5-7]. Moreover, like diseases caused by conventional agents, prion diseases can be transmitted between hosts via natural routes. In a striking resemblance of strain phenomenon of viral and microbial pathogens, multiple strains of prions or $\mathrm{PrP}^{\mathrm{Sc}}$ that invade and replicate within the same host species were identified [8]. Prion strain of natural origin including mouse strains used in the current study were originally isolated from animals that succumbed to prion disease and then adapted to rodents via serial passaging [9-11]. Different strains elicit different, strain-specific disease phenotypes, characterized by strain-specific incubation time to disease, tropism to different brain areas and strain-specific tropism to different cell types [7,8,12]. The diversity of disease phenotypes within the same host is attributed to the ability of $\mathrm{PrP}^{\mathrm{C}}$ to acquire multiple, alternative, conformationally distinct, self-replicating $\operatorname{PrP} \mathrm{P}^{\mathrm{Sc}}$ states or strains [13-18]. Indeed, a number of studies provided solid evidence that that prion strains 
are different with respect to their biochemical properties as well as secondary, tertiary and quaternary structure [17,19-23]. While structural diversity of $\mathrm{PrP}^{\mathrm{Sc}}$ strains has been well documented [19-21], the questions why and how multiple $\mathrm{PrP}^{\mathrm{Sc}}$ structures, formed within the same amino acid sequence, elicit multiple disease phenotypes or target different brain areas remains poorly understood.

Two major types of posttranslational modifications, an attachment of the GPI anchor and N-linked glycosylation, were found in $\operatorname{PrP}^{\mathrm{C}}$ [24-26]. The majority of $\operatorname{PrP}^{\mathrm{C}}$ is diglycosylated (up to $80 \%$ ), whereas a small fraction is monoglycosylated and very minor amount is unglycosylated [27]. In $\operatorname{PrP}^{\mathrm{C}} \mathrm{N}$-linked glycans, sialic acids are terminal residues that are linked to galactose via $\alpha 2-3$ or $\alpha 2-6$ linkages with the majority being linked via $\alpha 2-6$ linkage $[25,28,29]$. More than 400 different $\operatorname{PrP}^{\mathrm{C}}$ glycoforms have been identified, the heterogeneity attributed to the variations in structure and composition of the N-linked glycans $[25,28]$. The GPI-anchor and N-linked glycans are preserved upon conversion of $\operatorname{PrPC}^{\mathrm{C}}$ into $\mathrm{PrPSc}^{\mathrm{S}}[30-32]$.

Upon conversion of $\operatorname{PrP}^{\mathrm{C}}$ into $\mathrm{PrPSc}, \mathrm{N}$-linked glycans are positioned on a surface of $\mathrm{PrP} \mathrm{PS}^{\mathrm{S}}$ particles and impose considerable spatial constrains to $\operatorname{PrP}^{\mathrm{Sc}}$ assembly due to their bulky size and electrostatic repulsion between sialic acid residues [33,34]. In some strains, sialoglycoforms are recruited proportionally to their representation in $\operatorname{PrP}^{\mathrm{C}}[27,33]$. However, there are strains that exhibit a selectivity. Such strains preferentially recruit monoglycosylated and moderately sialylated $\operatorname{Pr} \mathrm{P}^{\mathrm{C}}$ molecules at the expenses of diglycosylated and highly sialylated $\operatorname{PrP}^{\mathrm{C}}$ glycofoms, which helps to overcome spatial and electrostatic restrains [27,33]. Strain-specific selection of $\operatorname{PrP}^{\mathrm{C}}$ sialoglycoforms produces strain-specific patterns of carbohydrate epitopes on the surface of $\operatorname{PrP}^{\mathrm{Sc}}$ [35].

Are carbohydrate groups on $\mathrm{PrP}^{\mathrm{Sc}}$ surfaces important in eliciting biological response? The innate immune system is believed to sense terminal carbohydrate moieties including galactose and sialic acid residues. These groups are likely to serve as molecular cues and can trigger diverse responses by glia [36-40]. Sialic acid residues, which are abundant on the surfaces of all mammalian cells, act as a part of "self-associated molecular pattern" helping cells of the innate immune system including microglia to recognize "self" from "altered self" or "non-self" [41,42]. "Eat me" signals for professional and non-professional macrophages could be generated by galactose exposed on a cell surface upon removal of sialic acid residues [43,44]. As terminal residues, sialic acids are positioned on a surface of $\mathrm{PrP}^{\mathrm{Sc}}$ particles, and are accessible for intermolecular interactions [34]. Recent studies from our laboratory revealed that sialylation of $\mathrm{PrP}^{\mathrm{Sc}} \mathrm{N}$-linked glycans plays an important role in controlling prion fate in an organism [33,45-48]. Donor $\mathrm{PrP}^{\mathrm{Sc}}$ with reduced sialylation levels did not induce prion disease in animals upon intracranial or peripheral administration $[45,47,48]$. Moreover, prion infectivity could be switched off and on in a reversible manner via removing and reinstalling sialylation of $\mathrm{PrP}^{\mathrm{Sc}}$, respectively [47]. Sialylation status of $\mathrm{PrP}^{\mathrm{Sc}}$ was also found to be important for prion lymphotropism $[46,48]$. Upon infection via peripheral route, $\mathrm{PrPSc}^{\mathrm{Sc}}$ with normal sialylation status was sequestered by spleen and lymph nodes, whereas partially desialylated $\mathrm{PrP}^{\mathrm{Sc}}$ was targeted predominantly to the liver [48]. Together, these studies suggested that sialylation protects $\mathrm{PrP}^{\mathrm{Sc}}$ against clearance and appears to be critical in controlling the fate of prion infection in an organism.

Prion strains are known to invade brain regions in a strain-specific manner, a phenomenon referred to as selective neurotropism $[49,50]$. Closely related to this phenomenon is selective vulnerability of brain regions to prion infection, where some regions are being affected more severely than others. Molecular mechanisms underlying selective vulnerability are not well understood. It is not known whether $\mathrm{PrP}^{\mathrm{Sc}}$ sialylation is involved in defining differential response of brain region to prion infection. While high sialylation levels of $\mathrm{PrP}^{\mathrm{Sc}}$ appears to be critical for prion survival on the one hand $[45,47,48]$, a decrease in sialylation level of $\operatorname{PrP}^{\mathrm{C}}$ increase prion replication rate on the other hand [27,45]. It is not known whether strain-specific sialylation pattern of $\mathrm{PrP}^{\mathrm{Sc}}$ is maintained across all brain region or whether region-specific differences exists. The current work demonstrated that $\mathrm{PrP}^{\mathrm{Sc}}$ is sialylated in a region-dependent manner. Similar trends were observed in brain materials from 22L-, RMLand ME7-infected animals. The current study established that $\operatorname{PrP}^{\mathrm{Pc}}$ sialylation status is indeed region-specific. Together with previous studies demonstrating that low sialylation status accelerates 
prion replication, this work suggests that high vulnerability of certain brain region to prion infection is attributed to their low sialylation status.

\section{Results}

\subsection{Strain-Specific Sialylation Patterns of $\operatorname{Pr} P^{S c}$}

To illustrate strain-specific sialylation patterns of $\mathrm{PrPSc}$, scrapie brain homogenates from animals infected with three mouse-adapted prion strains (22L, ME7 and RML) were analyzed using two-dimensional (2D) gel electrophoresis (Figure 1) [51]. Prior to 2D gel electrophoresis, the samples were denatured, so that the sialylation status of individual PrP molecules could be visualized as a distribution of charge isoforms in the horizontal dimension of 2D [51]. Since each sialic acid residue adds negative charges to individual PrP molecules, hypersialylated PrP molecules run toward acidic $\mathrm{pH}$ whereas hyposialylated toward basic $\mathrm{pH}$. Three horizontal rows of charged isoforms corresponded to the non-, mono- and diglycosylated PrP molecules. Consistent with previous studies [27,46,52,53], non-glycosylated PrP molecules showed multiple charge isoforms on 2D (Figure 1). The structural heterogeneity of the GPI anchors, which could be also sialylated, account for this charge heterogeneity $[54,55]$. In RML material, monoglycosylated sialoglycoforms dominated over the diglycosylated sialoglycoforms, whereas diglycosylated glycoforms were predominant in both ME7 and 22L. Moreover, the hyposialylated isoforms were populated at a higher level in RML versus 22L and ME7. 22L and ME7 displayed very similar profiles of sialoglycoforms, nevertheless, ME7 showed the lowest ratio of non- and monoglycosylated versus diglycosylated glycoforms among the three strains (Figure 1).

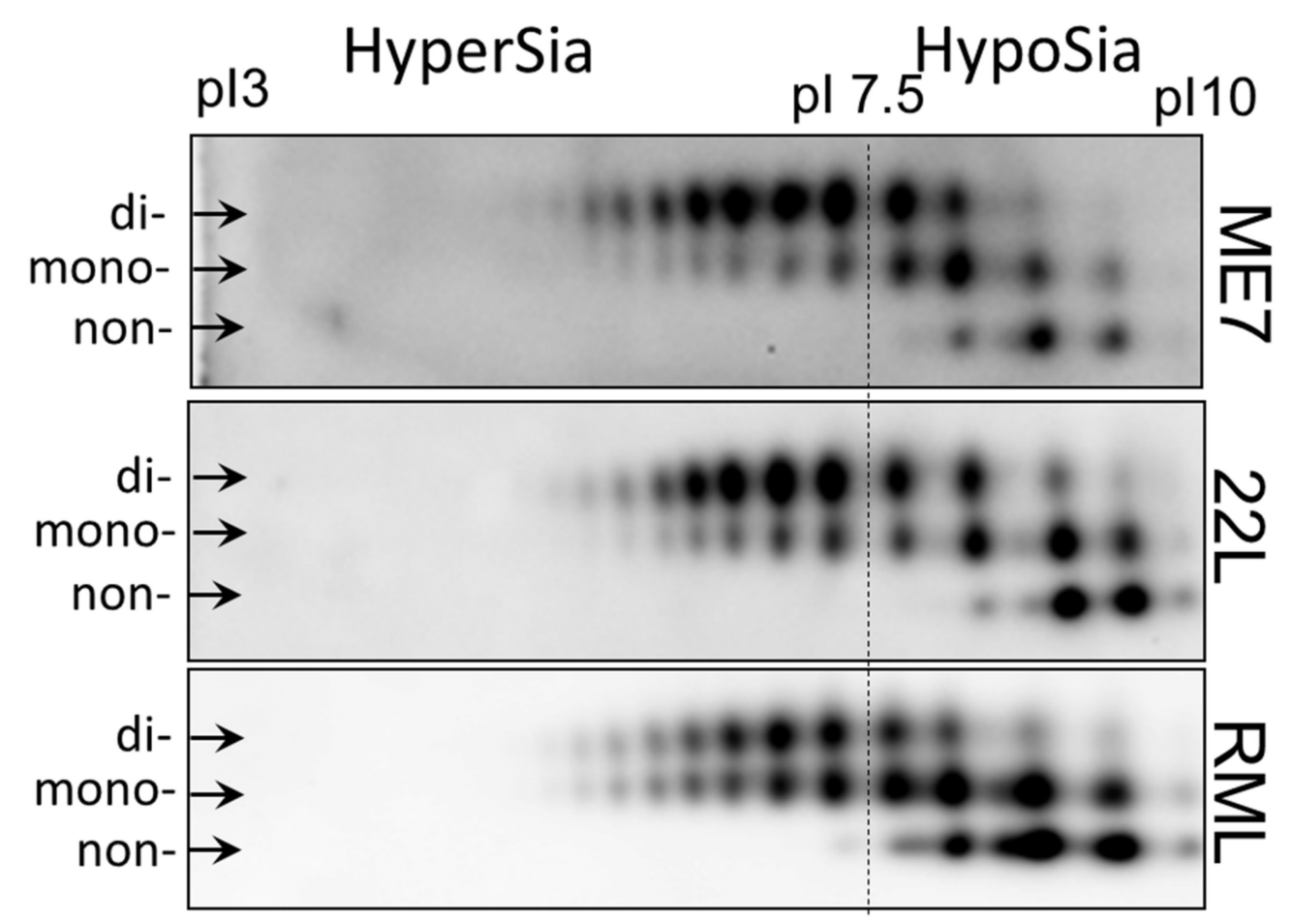

Figure 1. Analysis of strain-specific sialylation status of $\mathrm{PrPSc}$. Two-dimensional (2D) analysis of $\mathrm{PrP}^{\mathrm{Sc}}$ from whole brain homogenate of animals infected with 22L, ME7 and RML. The samples were treated with PK. Anti-PrP antibody ab3531 were used for immunodetection. Arrows point at di-, monoand non-glycosylated glycoforms. The dash line shows the position of pI 7.5 and arbitrary divides hypersialylated and hyposialylated PrP molecules. Appearance of more than one charge isoforms for non-glycosylated $\mathrm{PrP}$ is attributed to a structural heterogeneity of the GPI anchor [54]. As a result of N-glycan sialylation, the position of mono- and diglycosylated PrP isoforms is shifted toward acidic pH, in comparison non-glycosylated PrPs. Adapted from Katorcha et al. 2015 [27]. 
In summary, 2D analysis demonstrated subtle, yet notable differences between sialylation patterns of $\mathrm{PrP}^{\mathrm{Sc}}$ of three strains. Next, we asked whether strain-specific sialylation patterns are preserved across brain regions. As an alternative possibility, $\mathrm{PrP}^{\mathrm{Sc}}$ sialylation patterns might change with a region. If this is the case, the strain-specific sialylation pattern of $\mathrm{PrP}^{\mathrm{Sc}}$ of a whole brain represents a weighted average of the region-specific $\mathrm{PrP}^{\mathrm{Sc}}$ sialylation patterns.

\subsection{Region-Specific Sialylation of $\operatorname{Pr} P^{S c}$}

For examining region-specific sialylation patterns, four brain regions including cortex, hippocampus, thalamus and stem from animals infected with $22 \mathrm{~L} \operatorname{PrP}^{\mathrm{Sc}}$ were analyzed using 2D. Preliminary studies revealed that by the terminal stage of the diseases, $22 \mathrm{~L} \operatorname{PrP}^{\mathrm{Pc}}$ accumulated throughout the brain (Figure 2A-K). Western blotting showed comparable amounts of $\mathrm{PrP}^{\mathrm{Sc}}$ in cortex, hippocampus, thalamus and stem (Figure 2A). Immunohistochemistry confirmed $\mathrm{PrP}^{\mathrm{Sc}}$ deposition in all four brain regions, and revealed several types of $\mathrm{PrP}^{\mathrm{Sc}}$ aggregates including diffuse and punctate deposits and small plaques (Figure 2B-K). 

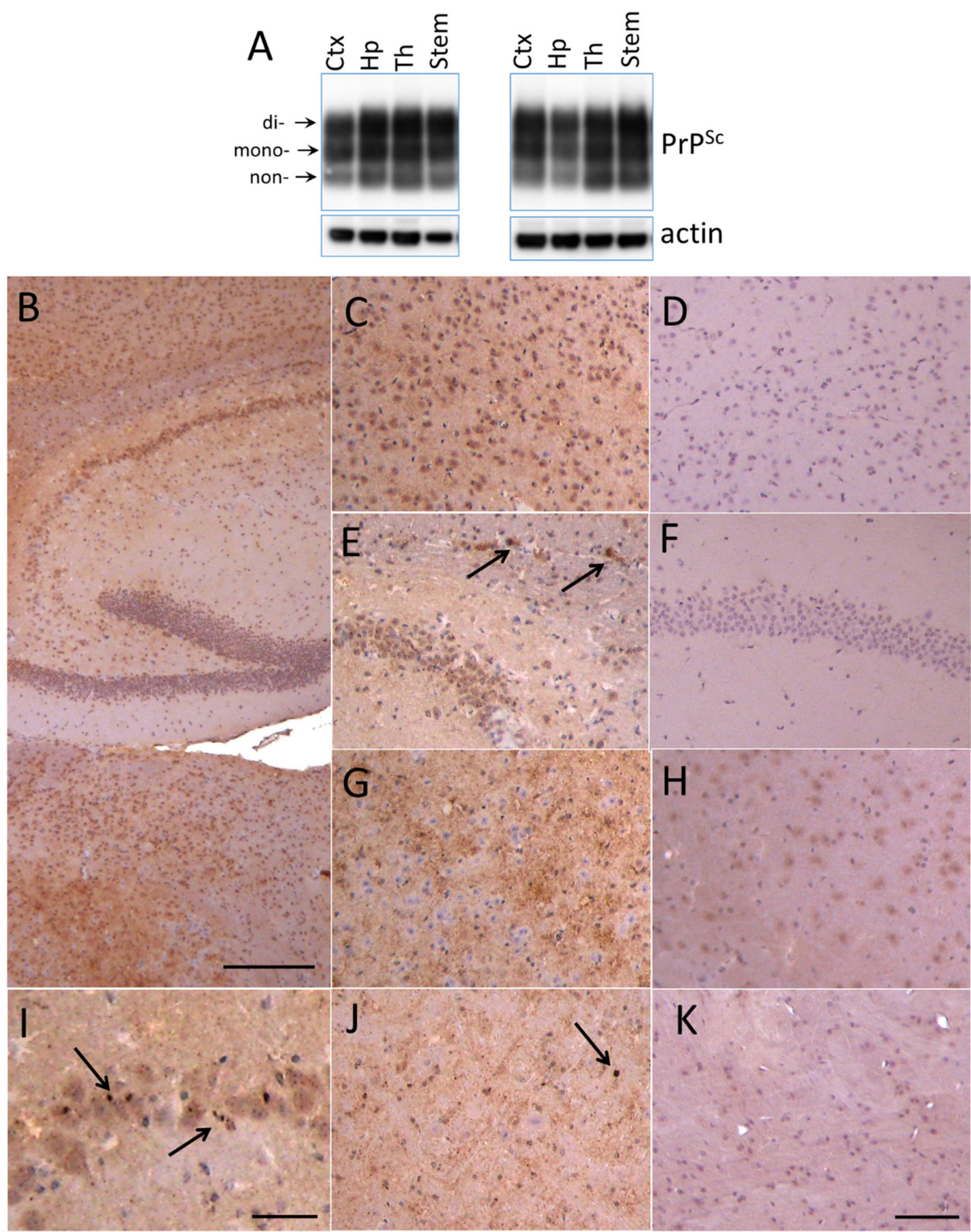

Figure 2. Deposition of $22 \mathrm{~L} \mathrm{PrP}^{\mathrm{Sc}}$ in four brain regions. (A) Western blot analysis of $22 \mathrm{~L} \operatorname{Pr} \mathrm{P}^{\mathrm{Sc}}$ deposition in cortex (Ctx), hippocampus (Hp), thalamus (Th) and stem of two terminally sick animals. Prior to Western blot of $\mathrm{PrPSc}^{\mathrm{Sc}}$, brain material was treated with $20 \mu \mathrm{g} / \mathrm{mL}$ PK. Western blots were stained with anti-prion antibody ab3531. Arrows point at di-, mono- and non-glycosylated glycoforms. (B-K) Immunohistochemistry with SAF-84 showing $\mathrm{PrP}^{\mathrm{Sc}}$ deposition in hippocampus (B,E,I), cortex $(\mathbf{C})$, thalamus $(\mathbf{B}, \mathbf{G})$ and stem $(\mathrm{J})$ of $22 \mathrm{~L}$-infected animals in comparison with corresponding regions of normal aged animals $(\mathbf{D}, \mathbf{F}, \mathbf{H}, \mathbf{K})$. Arrows focus on small plaques in the corpus callosum (E) and small granular deposits in pyramidal layer of hippocampus (I) and in stem (J). Scale bars: $300 \mu \mathrm{m}$ on B, $100 \mu \mathrm{m}$ on $\mathbf{C}-\mathbf{H}$, J and $\mathbf{K}, 50 \mu \mathrm{m}$ on $\mathbf{I}$.

Comparison of cortex, hippocampus, thalamus and stem on 2D revealed differences in relative intensities of individual sialoglycoforms, which appeared to be subtle upon initial observation 
(Figure 3A). For visualizing the difference in more details, we applied artificial color assignment using Alpha View software, and analyzed three series of glycoforms (di-, mono and unglysocylated) separately (Figure 3B). Despite variations between animals, brain regions in individual animals displayed the same ranking order with respect to levels of sialylation within populations of di- and monoglycoylated glycoforms (from the most hypersialylated to hyposialylated): hippocampus = cortex $>$ thalamus $>$ stem (Figure 3B,C). In contrast to di- and monoglycosylated isoforms, the distribution of non-glycosylated charged isoforms, that lacked $\mathrm{N}$-glycans, was very similar across brain regions, confirming that the differences in charge isoform distributions within di- or mono-glycoforms are attributed to $\mathrm{N}$-linked glycans (Figure 3B,C). These results suggest that the sialylation of $\mathrm{PrP}^{\mathrm{Sc}} \mathrm{N}$-glycans varies in a region-specific manner and that in hippocampus and cortex $\mathrm{PrPSc}^{\mathrm{Sc}}$ was sialylated at higher levels than in thalamus and stem. 

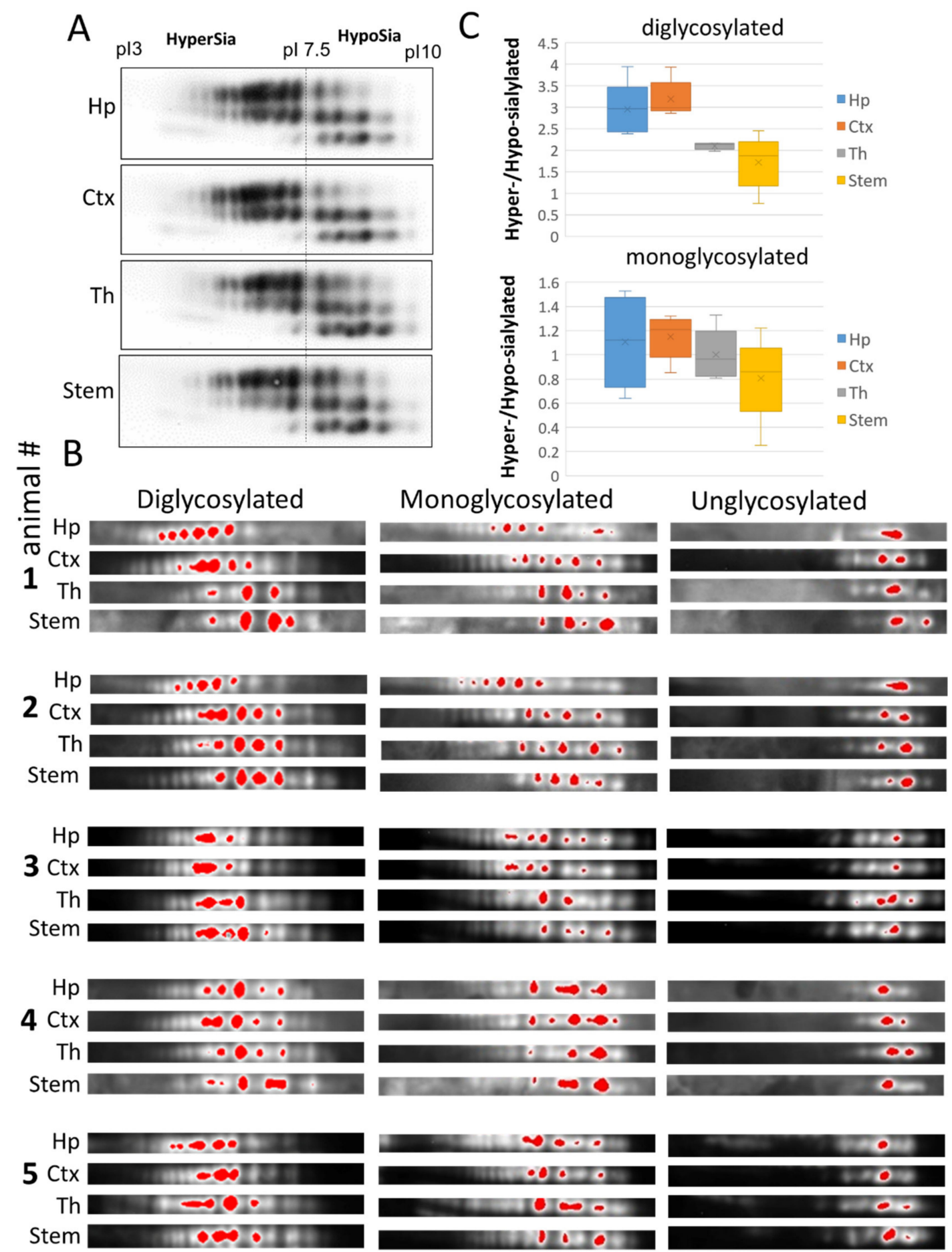

Figure 3. Analysis of sialylation status of $\mathrm{PrP}^{\mathrm{Sc}}$ from four brain regions of 22L-infected animals. (A) Representative 2D Western blot of $\mathrm{PrP}^{\mathrm{Sc}}$ from hippocampus (Hp), cortex (Ctx), thalamus (Th) and stem of 22L-infected animals. Prior to 2D blot, brain materials were treated with $20 \mu \mathrm{g} / \mathrm{mL}$ PK. (B) 2D Western blots of $\mathrm{PrP}^{\mathrm{Sc}}$ from hippocampus (Hp), cortex (Ctx), thalamus (Th) and stem grouped according to PrP glycosylation status (di-, mono- and unglycosylated, $n=5$ animals). Prior to $2 \mathrm{D}$ blot, brain materials were treated with with $20 \mu \mathrm{g} / \mathrm{mL} \mathrm{PK}$. Intensity of individual sialoglycoforms is visualized by red color using Alpha View software. (C) A box and whisker plot showing the ratio of hypersialylated versus hyposialylated $\mathrm{PrP}^{\mathrm{Sc}}$ in hippocampus ( $\left.\mathrm{Hp}\right)$, cortex (Ctx), thalamus (Th) and stem. Diglycosylated and monoglycosylated sialoglycoforms are analyzed separately. The mean (x), the minimal and maximal values (the vertical line), and the medians of the bottom and the top half (the bottom and top lines of the box, respectively) are shown ( $n=5$ animals). The ratio of hypersialylated versus hyposialylated isoforms is calculated as described in Materials and Methods. 
For testing whether the ranking order of $\mathrm{PrP}^{\mathrm{Sc}}$ sialylation is strain-specific or universal, we analyzed brains of animals infected with two additional mouse strains RML and ME7. Because only few brains were available for 2D analysis, statistical differences could not be established. Nevertheless, brain regions from RML and ME7 animals showed the same ranking order with respect to the sialylation levels as 22L-infected animals (Figure 4A,B). Together, these data suggest that sialylation levels of $\mathrm{PrP}^{\mathrm{Sc}}$ are region-dependent.
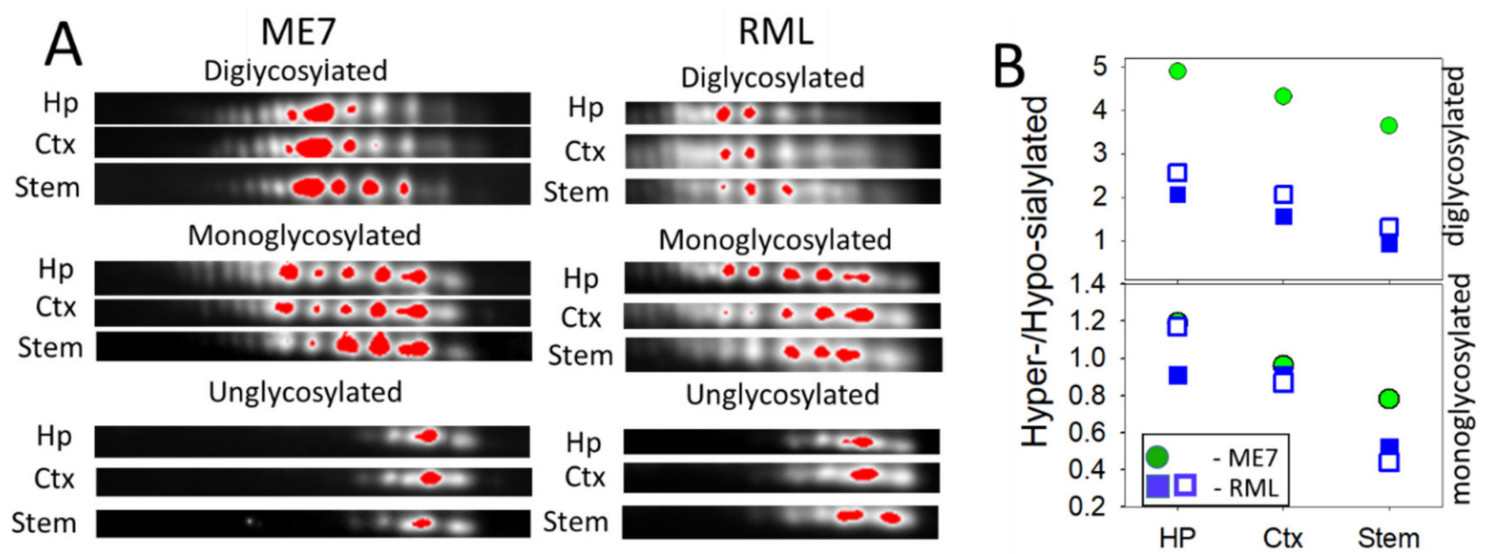

Figure 4. Analysis of sialylation status of $\mathrm{PrPSc}^{\mathrm{Sc}}$ from ME7- and RML-infected animals. (A) 2D Western blot analysis of charge distribution of $\operatorname{PrP}^{\mathrm{Sc}}$ sialoglycoforms from hippocampus (Hp), cortex (Ctx), and stem. Prior to 2D blot, brain materials were treated with $20 \mu \mathrm{g} / \mathrm{ml} \mathrm{PK}$. Intensity of individual sialoglycoforms is visualized by red color using Alpha View software. (B) A plot showing the ratio of hypersialylated versus hyposialylated $\mathrm{PrP}^{\mathrm{Sc}}$ in hippocampus $(\mathrm{Hp})$, cortex $(\mathrm{Ctx})$ and stem in ME7-infected animal (circles, $n=1$ ) and RML-infected animals (squares, $n=2$ ). Diglycosylated and monoglycosylated sialoglycoforms are analyzed separately. The ratio of hypersialylated versus hyposialylated isoforms is calculated as described in Materials and Methods.

\subsection{Region-Specific Expression of Sialyltransferases}

In a cell, steady state sialylation status of glycoproteins is determined by two groups of enzymes: sialyltransferases (ST), which transfer sialic acid residues to glycans, and neuraminidases or sialidases, which cleave sialic acid residues [56,57]. Our previous studies demonstrated that knocking down of sialidases that expressed in CNS (Neu1, Neu3, Neu4 or Neu3/Neu4 double knockouts) did not affect the steady-state sialylation levels of $\mathrm{PrPC}^{\mathrm{C}}$ [58]. Among a large class of mammalian STs, five STs display a substrate specificity for sialylating N-linked glycans via $\alpha 2-3$ or $\alpha 2-6$ linkages, the type of linkages identified in $\mathrm{PrPC}^{\mathrm{C}}$ and $\operatorname{PrPSc}^{\mathrm{Sc}}[2,28,29]$. Three STs of the ST3 family (ST3Gal3, ST3Gal4 and ST3Gal6) sialylate via $\alpha 2-3$ linkages, whereas two STs of the ST6 family (ST6Gal1 and ST6Gal2) use 22-6 linkages [57,59].

For testing whether region-specific differential sialylation of $\mathrm{PrP}^{\mathrm{Sc}}$ could be attributed to the region-specific expression level of STs, mRNA expressions of ST3Gal3, ST3Gal4, ST3Gal6, ST6Gal1 and ST6Gal2 were analyzed in hippocampus, cortex, thalamus and stem using qRT-PCR. In addition, we were interested in finding out whether different brain regions have differential expression of these STs under normal condition, and whether their expression changes with the prion disease. ST3Gal3, ST3Gal4 and ST3Gal6 levels of expression did not show reliable differences between brain regions neither in normal nor in infected animals (Figure 5A). ST6Gal1 was the only gene that showed a significant increase in the prion-infected animals versus normal age-matched controls (Figure 5B), which was consistent with previous observations [60]. Another $\alpha-2,6$-syaliltransferase, ST6Gal2, was expressed at much lower levels than ST6Gal1 when compared to the housekeeping gene, yet was the only one displaying moderate region-specific differences in the expression level (Figure 5B). The region-specific differences in mean ST6Gal2 expression values, while showing a higher expression levels in cortex relative to other regions, did not prove to be statistically significant. However, the ST6Gal2 expression 
in individual animals consistently followed a similar pattern where the cortex displayed the highest level of ST6Gal2 expression (Figure 5C). While analysis of STs expression does not explain relative ranking of brain region with respect to $\mathrm{PrP}^{\mathrm{Sc}}$ sialylation, these data suggest that ST6Gal2 might be responsible in part for region-specific differences in sialylation of $\mathrm{PrP}^{\mathrm{Sc}}$.
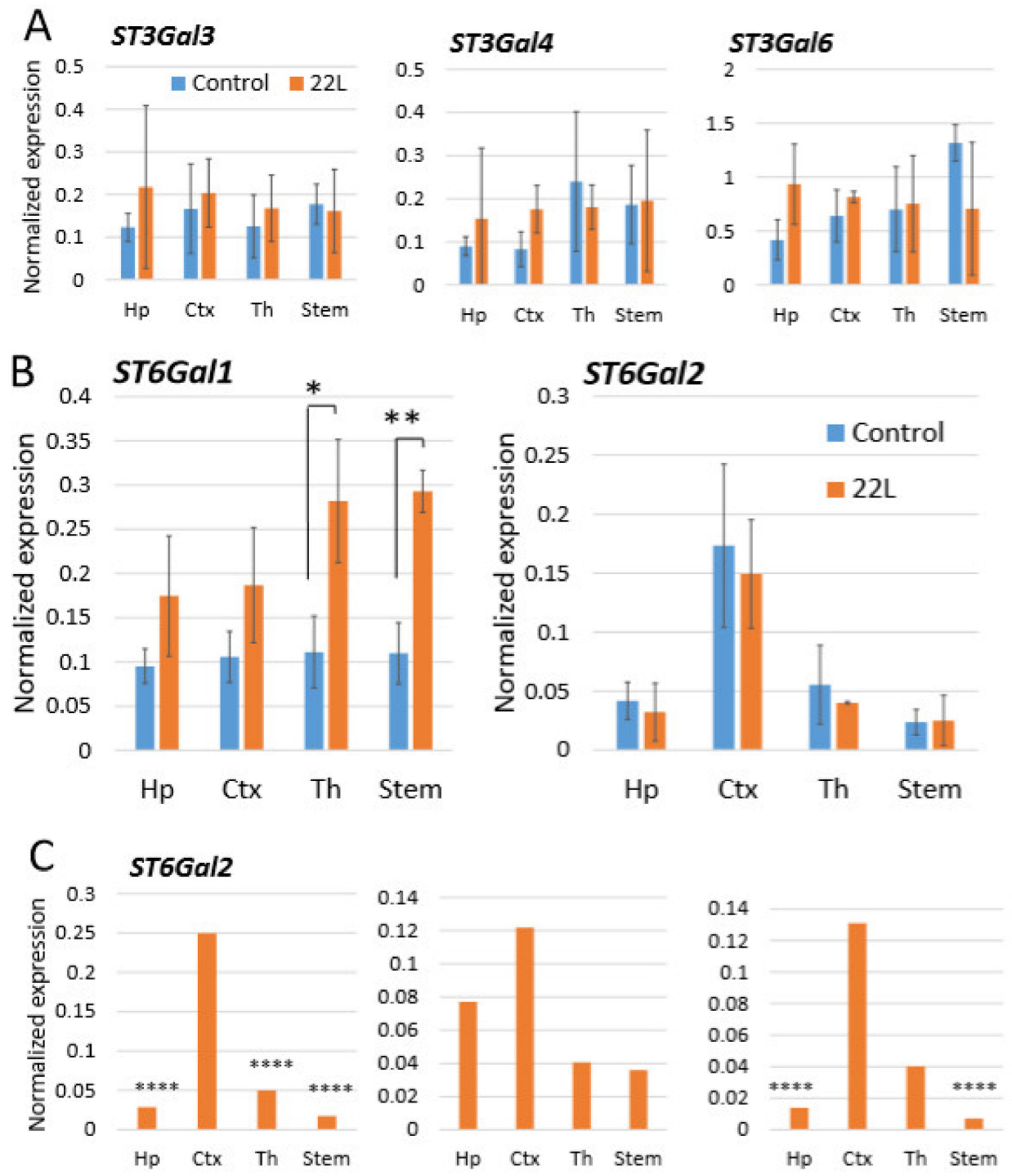

Figure 5. Analysis of gene expression by qRT-PCR. Expression of ST3Gal3, ST3Gal4 and ST3Gal6 (A), and ST6Gal1 and ST6Gal2 (B) in hippocampus (Hp), cortex (Ctx), thalamus (Th) and stem of 22L-infected animals or normal age-matched controls normalized by the expression of housekeeping gene TBP. The mean and standard deviation are shown ( $n=3$ animals). (C) Expression of ST6Gal2 in hippocampus (Hp), cortex (Ctx), thalamus (Th) and stem of three individual 22L-infected animals normalized by the expression of housekeeping gene TBP. Statistical significance between the groups in (A) and (B) was calculated by Student's unpaired t-test and indicated as * for $p<0.05$ and ${ }^{* *}$ for $p$ $<0.01$; in $(\mathbf{C}),{ }^{* * * *}$ indicates $p<0.0001$ significance of differences (threshold regulation $=4$ ) between samples analyzed in triplicate, and was calculated by BioRad CFX Manager.

\section{Discussion}

Recent discovery highlighted an important role of $\mathrm{PrP}^{\mathrm{Sc}}$ sialylation in determining the rate of prion replication and their fate in an organism, shedding a new light on prion pathogenesis $[27,33,40,45-48]$. Considering that prion deposition in brain selectively targets specific regions and that brain regions display differential vulnerability to prion infection $[7,8,12]$, we decided to look into the possibility 
that sialylation of $\operatorname{PrP}^{\mathrm{Sc}}$ might be important in defining selective vulnerability. Consistent with this hypothesis is a previous work illustrating that in mice with deficient $\operatorname{PrP}^{\mathrm{C}}$ glycosylation regional distribution of $\mathrm{PrP}^{\mathrm{Sc}}$ and lesion profile underwent significant changes [61]. Within the current study, we asked the question whether $\mathrm{PrP}^{\mathrm{Sc}}$ sialylation is uniform across brain regions or region-specific. Analysis of $22 \mathrm{~L}$-infected animals revealed that $\mathrm{PrP}^{\mathrm{Sc}}$ is sialylated in a region-specific manner. This observation is consistent with the hypothesis in that a link between $\operatorname{PrP}^{\mathrm{PC}}$ sialylation and differential vulnerability exist.

Despite variations in $\mathrm{PrP}^{\mathrm{Sc}}$ sialylation pattern between individual 22L-infected animals, the common trend emerged upon analysis of this animal group. $\mathrm{PrP}^{\mathrm{Sc}}$ deposited in hippocampus and cortex was found to be more sialylated than $\mathrm{PrP}^{\mathrm{Sc}}$ from thalamus and stem. Similar trends were observed in brains from RML- and ME7-infected animals: $\mathrm{PrP}^{\mathrm{Sc}}$ from cortex and hippocampus was more sialylated than $\mathrm{PrP}^{\mathrm{Sc}}$ from stem. For RML and ME7 animals, statistically sound differences between brain regions could not be established, because only two and one animals, respectively, from those groups were available for analysis. Nevertheless, based on 22L data, this work indicates that in addition to strain-specific differences, $\mathrm{PrP}^{\mathrm{Sc}}$ sialylation pattern is controlled by a brain region.

The regional differences in sialylation status of $\mathrm{PrP}^{\mathrm{Sc}}$ are possibly attributed to regional differences in sialylation of $\operatorname{PrPC}^{\mathrm{C}}$, a substrate of $\operatorname{PrP}^{\mathrm{Sc}}$ replication. The fact that all three prion strains show similar trends supports this idea. Unfortunately, assessing sialylation status of $\operatorname{PrP}^{\mathrm{C}}$ was proven to be very difficult due to uncanonical behavior of octarepeat region in isoelectric focusing [45,51,58]. In $\mathrm{PrP}^{\mathrm{Sc}}$, the octarepeat is cleaved by proteinase $\mathrm{K}$ prior to $2 \mathrm{D}$, which result in a well-defined positioning of individual sialoglycoform on the horizontal dimension of 2D [51].

What enzymes control sialylation status of N-linked glycans? In our previous studies, knocking down CNS sialidases in animals (Neu1, Neu3, Neu4 or Neu3/Neu4 double knockouts) did not change the steady-state sialylation levels of $\operatorname{PrP}^{\mathrm{C}}$ [58]. In the current work, we tested whether region-specific differences in sialylation of $\mathrm{PrP}^{\mathrm{Sc}}$ correlate with regional expression of those STs that sialylate N-linked glycans via $\alpha 2-3$ or $\alpha 2-6$ linkages (ST3Gal3, ST3Gal4, ST3Gal6, ST6Gal1 and ST6Gal2). All three ST3s tested (ST3Gal3, ST3Gal4, ST3Gal6) displayed large variations between individual animals, but no consistent correlation with the regional sialylation levels of $\mathrm{PrP}^{\mathrm{Sc}}$. ST6Gal1 showed a statistically significant increase in expression levels in 22L-infected versus age-matched control animals at least in two brain areas, which was consistent with previous studies [60]. However, no correlation between regional ST6Gal1 expression and sialylation levels of $\mathrm{PrPSc}^{\mathrm{Sc}}$ was observed. The data on expression of STs mRNAs should be considered with a great caution, because mRNA level might not reflect the level of sialyltransferase enzymatic activity.

Notably, expression of ST6Gal2 was higher in cortex, a region with high sialylation status of $\mathrm{PrPSc}$, relative to hippocampus, thalamus and stem. While ST6Gal1 gene is expressed in almost all human tissues, ST6Gal2 shows a restricted tissue-specific pattern and mostly expressed in embryonic and adult brain [62]. Nevertheless, the substrate specificity of ST6Gal2 enzyme is not well understood. Recombinant ST6Gal2 was found to exhibit high sialyltransferase activity toward oligosaccharides; however, its activity toward glycoproteins was very low [63,64]. Several transcriptional activators and repressors of ST6gal2 gene including NF- $\mathrm{kB}$ repressor were identified suggesting that ST6gal2 transcription is regulated in a function dependent manner. The current work suggests that region-specific differences in sialylation of $\mathrm{PrP}^{\mathrm{Sc}}$ might be attributed, at least in part, to differential expression of ST6Gal2 in brain regions. It would be interesting to test the effect of ST6Gal2 knock out on $\mathrm{PrP}^{\mathrm{Sc}}$ sialylation and prion propagation. Differences in region-specific stability of hypersialylated versus hyposialylated $\mathrm{PrP}^{\mathrm{C}}$ offers an alternative hypothesis for explaining region-specific differences in sialylation of $\mathrm{PrP}^{\mathrm{Sc}}$. The third range of possibilities involves region-specific differences in N-glycan structures. Structural differences might be attributed to (i) regional differences in the ratios of bi- vs. three- and tetra-antennary N-glycan branches leading to a different number of potential sialylation sites for each glycan, and/or (ii) the degree of galactosylation of each antennary termini, as lack of 
galactosylation would prevent subsequent sialylation. The last mechanism was found to control sialylation status of $\mathrm{N}$-glycans on IgG [65].

Do brain areas respond differently to prion infection? Why are some brain regions more vulnerable to prion infection than others? Recent studies illustrated that astrocytes respond to prion infection in a region-specific manner $[66,67]$. Transcriptome analysis and single-cell RNA-sequencing demonstrated great region-specific heterogeneity in phenotypes of microglia and astrocyte under normal conditions as well as revealed dynamic transformation of their phenotypes under aging and neurodegenerative diseases [68-73]. Expression of genes associated with neuroinflammation, synapse elimination and neuronal damage were found to be elevated in normal aging [70-72]. Notably, the rates of astrocyte aging under normal conditions vary as a function of brain region [72]. Considering that the mean age of onset of sporadic CJD is 66 years old, in humans the age-related changes in glia should be taken into consideration. However, the extent to which age-related changes in microglia or astrocytes contribute to region-specific susceptibility to prion infection in mice is questionable, because animal progress to terminal stage much earlier than the age-related changes take place.

In 22L-infected animals, the thalamus display prion deposition and chronic neuroinflammation prior to cortex and hippocampus $[7,74]$. Moreover, by the terminal stage of the disease, the thalamus is affected more severely than other brain regions [7,74]. In mice, high vulnerability of thalamus to prion infection was found to be irrespective of a prion strain $[7,12,66,74,75]$. What, then, makes the thalamus so vulnerability to prion invasion and chronic neuroinflammation? The current study demonstrated that $\mathrm{PrP}^{\mathrm{Sc}}$ from thalamus and stem had lower sialylation levels relative to $\mathrm{PrP}^{\mathrm{Sc}}$ from cortex or hippocampus (Figure 3). Considering that low sialylation status accelerates prion replication [27,45], the results of the current work suggest that thalamus and stem are more vulnerable to prion infection due to its low sialylation status. In addition to plausible region-specific differences in replication rates, sialylation status of $\mathrm{PrP}^{\mathrm{Sc}}$ might impact the severity of pathogenesis via controlling the pro-inflammatory response of microglia. Results of our recent study provide experimental support behind this hypothesis [40]. Partial desialylation of $\mathrm{PrP}^{\mathrm{Sc}}$, which results in an increase in the number of galactose residues at the terminal position of $\mathrm{PrP}^{\mathrm{Sc}} \mathrm{N}$-linked glycans, was found to boost the pro-inflammatory response of microglia [40]. Together with previous work, the current study suggests that region-specific differences in sialylation might be important factor in controlling the timing and severity of prion pathogenesis.

Since $\mathrm{PrP}^{\mathrm{Sc}}$ sialylation patterns is determined to large extent by a region, the strain-specific sialylation of $\mathrm{PrP}^{\mathrm{Sc}}$ of a whole brain represent a weighted average of the region-specific $\mathrm{PrP}^{\mathrm{Sc}}$ sialylation patterns for each individual strain. We propose that strains that can tolerate hypersialylated $\operatorname{PrPC}$ molecules as a substrate are better positioned to spread into brain regions expressing hypersialylated $\mathrm{PrP}^{\mathrm{C}}$ relative to the strains that are more selective with respect to $\mathrm{PrP}^{\mathrm{C}}$ sialylation status. Whether this is the case will have to be determined in future studies.

\section{Materials and Methods}

\subsection{Ethics Statement}

This study was carried out in strict accordance with the recommendations in the Guide for the Care and Use of Laboratory Animals of the National Institutes of Health. The animal protocol was approved by the Institutional Animal Care and Use Committee of the University of Maryland, Baltimore (Assurance Number A32000-01; Permit Number: 0118001).

\subsection{Animals}

C57BL/6J mice (females and males) were inoculated intracerebrally into the left hemisphere $\sim 2 \mathrm{~mm}$ to the left of the midline and $\sim 2 \mathrm{~mm}$ anterior to a line drawn between the ears with $20 \mu \mathrm{L}$ of $1 \% 22 \mathrm{~L}$ brain homogenate under isoflurane anesthesia. Inoculum is delivered slowly by a $26 \mathrm{G}$ needle inserted to a depth of approximately $3 \mathrm{~mm}$. Signs of neurological disease were detected between 132-138 days post inoculation and consisted of hind-limb clasp, ataxia and weight loss. Within 13-23 days after 
first clinical sings, mice became unable to walk on a beam, developed kyphosis and became lethargic. Mice were considered terminally ill when they were unable to rear and/or lost $20 \%$ of their weight. At this point they were euthanized by $\mathrm{CO}_{2}$ asphyxia and decapitation.

\subsection{Histopathology}

Formalin-fixed brain halves divided at the midline (left hemispheres) were treated in formic acid (95\%) to deactivate prion infectivity before being embedded in paraffin. $4 \mu \mathrm{m}$ sections mounted on slides were processed for immunohistochemistry. To expose $\mathrm{PrPSc}^{\mathrm{Sc}}$ epitopes, slides were subjected to 20 min hydrated autoclaving at $121{ }^{\circ} \mathrm{C}$ in trisodium citrate buffer, $\mathrm{pH} 6.0$ with $0.05 \%$ Tween 20 , followed by $5 \mathrm{~min}$ treatment with $88 \%$ formic acid. PrP was stained with anti-prion antibody SAF- 84 (Cayman Chemical, Ann Arbor, MI, USA).

\section{4. $2 D$ Electrophoresis}

Brains were divided at the midline, and right hemispheres were used to dissect cortex, hippocampus, thalamus and stem. Each brain region was further divided into two pieces: one for protein electrophoresis, and another one for qRT-PCR (see below). 10\% (wt/vol) homogenates from each brain region were prepared within $1.5 \mathrm{~mL}$ tubes in ice-cold PBS, pH 7.4, using RNase-free disposable pestles (Fisher scientific, Hampton, NH, USA). To prepare samples for 2D electrophoresis, $10 \%$ homogenates were diluted with 9 volumes of $1 \%$ Triton X-100 in PBS, pH 7.4, and digested with $20 \mu \mathrm{g} / \mathrm{mL}$ PK for $30 \mathrm{~min}$ at $37^{\circ} \mathrm{C}$. The reaction was stopped by addition of NuPAGE LDS sample buffer (Thermo Fisher Scientific, Waltham, MA, USA) and a subsequent $10 \mathrm{~min}$ incubation in boiling water bath. After that, $25 \mu \mathrm{L}$ of samples in sample buffer were solubilized for $1 \mathrm{~h}$ at room temperature in $200 \mu \mathrm{L}$ solubilization buffer (8 M Urea, 2\% (wt/vol) CHAPS, $5 \mathrm{mM}$ TBP, $20 \mathrm{mM}$ TrisHCl pH 8.0), then alkylated by adding $7 \mu \mathrm{L}$ of $0.5 \mathrm{M}$ iodoacetamide and incubation for $1 \mathrm{~h}$ at room temperature in the dark. Then, $1160 \mu \mathrm{L}$ of ice-cold methanol was added and the samples were incubated for $2 \mathrm{~h}$ at $-20^{\circ} \mathrm{C}$. After $30 \mathrm{~min}$ centrifugation at $16,000 \mathrm{~g}$ at $4{ }^{\circ} \mathrm{C}$, the supernatant was discarded and the pellet was re-solubilized in $160 \mu \mathrm{L}$ rehydration buffer ( $7 \mathrm{M}$ urea, $2 \mathrm{M}$ thiourea, $1 \%$ (wt/vol) DTT, $1 \%$ (wt/vol) CHAPS, 1\% (wt/vol) Triton X-100, 1\% (vol/vol) carrier ampholytes $\mathrm{pH} 3-10$, trace amount of Bromophenol Blue). Fixed immobilized pre-cast IPG strips with a linear $\mathrm{pH}$ gradient 3-10 (cat. \# ZM0018, Thermo Fisher Scientific, Waltham, MA, USA) were rehydrated in $155 \mu \mathrm{L}$ of the resulting mixture overnight at room temperature inside IPG Runner cassettes (Thermo Fisher Scientific, Waltham, MA, USA). Isoelectrofocusing (first dimension separation) was performed at room temperature (175 V for $15 \mathrm{~min}$, then 175-2000 V linear gradient for $45 \mathrm{~min}$, then $2000 \mathrm{~V}$ for $30 \mathrm{~min}$ ) on Life Technologies Zoom Dual Power Supply, using the XCell SureLock Mini-Cell Electrophoresis System (Thermo Fisher Scientific, Waltham, MA, USA). The IPG strips were then equilibrated for 15 minutes consecutively in (i) $6 \mathrm{M} \mathrm{Urea,} \mathrm{20 \%} \mathrm{(vol/vol)} \mathrm{glycerol,} \mathrm{2 \%} \mathrm{SDS,} 375 \mathrm{mM}$ Tris- $\mathrm{HCl} \mathrm{pH} \mathrm{8.8,} 130 \mathrm{mM}$ DTT and (ii) $6 \mathrm{M}$ Urea, $20 \%$ (vol/vol) glycerol, 2\% SDS, $375 \mathrm{mM}$ Tris- $\mathrm{HCl} \mathrm{pH} \mathrm{8.8,} 135 \mathrm{mM}$ iodoacetamide, and loaded on 4-12\% Bis-Tris ZOOM SDS-PAGE pre-cast gels (Thermo Fisher Scientific, Waltham, MA, USA). For the second dimension, SDS-PAGE was performed for $1 \mathrm{~h}$ at $170 \mathrm{~V}$. Immunoblotting was performed as described elsewhere, blots were stained using ab3531 antibody (Abcam, Cambridge, MA, USA), visualized with FluorChem M FM 0512 imager and analyzed with AlfaView SA software (Protein Simple, San Jose, CA, USA).

For analysis of the hypersialylated versus hyposialylated isoform ratio, a previously published procedure was used [27]. Briefly, 2D blots were aligned horizontally and a line drawn at pI 7.5 was used to arbitrarily separate charge isoforms into hypersialylated and hyposialylated. In the software window, a rectangle was drawn to confine the spots of interest, and the densities were measured. The intensity of an equal background area from the same blot was subtracted before further analysis. The acquired spot ensemble intensities were used to calculate the ratio of hypersialylated isoforms over hyposialylated isoforms. 
For visualizing intensities of individual sialoglycoforms on 2D, Alpha View software was used for converting the intensity of the dots within each 2D blot to a size of red spots, so that the intensity of the original signal is proportional to the size of red area. Such procedure enabled an assessment of relative intensities of individual sialoglycoforms within one gel. The threshold was manually adjusted for each 2D blot until the red-colored spots in all the gels were in the same size range.

\section{5. $q R T-P C R$}

Tissue pieces of about $20 \mu \mathrm{g}$ from cortex, hippocampus, thalamus and stem were homogenized within $1.5 \mathrm{~mL}$ tubes in $200 \mu \mathrm{L}$ Trizol (Thermo Fisher Scientific, Waltham, MA, USA), using RNase-free disposable pestles (Fisher scientific, Hampton, NH, USA). An additional $600 \mu \mathrm{L}$ of Trizol was added, and the samples were centrifuged for $5 \mathrm{~min}$ at $12,000 \mathrm{~g}$. Clear supernatant was transferred to a new tube and thoroughly mixed with $160 \mu \mathrm{L}$ of cold chloroform. After $5 \mathrm{~min}$ incubation at room temperature, the samples were centrifuged for $15 \mathrm{~min}$ at $12,000 \mathrm{~g}$, and the clear top layer was transferred to a new tube and mixed with an equal volume of cold $70 \%$ ethanol. The resulting mixture was further processed with Aurum Total RNA Mini Kit (Bio-Rad, Hercules, CA, USA) to isolate total RNA. To exclude genomic DNA contamination, the samples were treated with DNase I Total RNA, was dissolved in elution buffer and stored at $-80^{\circ} \mathrm{C}$. An absorbance 260/280 value of 2.0, determined using NanoDrop ND-1000 Spectrophotometer (Thermo Fisher Scientific, Waltham, MA, USA), proved RNA purity. Reverse transcription was performed using $1 \mu \mathrm{g}$ of extracted RNA and iScript cDNA Synthesis Kit (Bio-Rad, Hercules, CA, USA). qRT-PCR was performed in triplicate from three normal and three prion-infected animals using SsoAdvanced Universal SYBR Green Supermix (Bio-Rad, Hercules, CA, USA) with Bio-Rad designed and validated primers: ST6Gal1 (qMmuCID0009827), ST6Gal2 (qMmuCED0046706), ST3Gal3 (qMmuCID0014977), ST3Gal4 (qMmuCID0007745) and ST3Gal6 (qMmuCED0046087). Housekeeping gene TBP (qMmuCID0040542) was used for normalization. The PCR protocol consisted of $95^{\circ} \mathrm{C}$ for $2 \mathrm{~min}$, followed by 40 amplification cycles with the following steps: $95^{\circ} \mathrm{C}$ for $5 \mathrm{~s}$, and $60^{\circ} \mathrm{C}$ for $30 \mathrm{~s}$. qRT-PCR was performed and analyzed using CFX96 Touch Real-Time PCR Detection System (Bio-Rad, Hercules, CA, USA), and plotted in Excel.

Author Contributions: Conceptualization, N.M. and I.V.B.; methodology, N.M.; validation, N.M. and J.C.-Y.C.; formal analysis, N.M. and J.C.-Y.C.; investigation, N.M. and J.C.-Y.C.; resources, N.M. and J.C.-Y.C.; writing-original draft preparation, I.V.B.; writing—review and editing, N.M. and J.C.-Y.C.; visualization, N.M. and I.V.B; supervision, I.V.B.; project administration, I.V.B.; funding acquisition, I.V.B. All authors have read and agreed to the published version of the manuscript.

Funding: This research was funded by the National Institute of Health Grants R01 NS045585 and R01 AI128925.

Conflicts of Interest: The authors declare no conflict of interest.

\section{Abbreviations}

$\begin{array}{ll}\text { 22L } & \text { Mouse-adapted prion strain } \\ \text { CNS } & \text { Central nervous system } \\ \text { ME7 } & \text { Mouse-adapted prion strain } \\ \text { qRT-PCR } & \text { Quantitative reverse transcription polymerase chain reaction } \\ \text { PK } & \text { Proteinase K } \\ \text { PrPC } & \text { Cellular isoform of the prion protein } \\ \text { PrPSc } & \text { Disease-associated: transmissible isoform of the prion protein } \\ \text { RML } & \text { Mouse-adapted prion strain } \\ \text { ST } & \text { Sialyltransferase } \\ \text { ST3Gal3 } & \text { ST3 beta-galactoside alpha-2,3-sialyltransferase 3 } \\ \text { ST3Gal4 } & \text { ST3 beta-galactoside alpha-2,3-sialyltransferase 4 } \\ \text { ST3Gal6 } & \text { ST3 beta-galactoside alpha-2,3-sialyltransferase 6 } \\ \text { ST6Gal1 } & \text { ST6 beta-galactoside alpha-2,6-sialyltransferase 1 } \\ \text { ST6Gal2 } & \text { ST6 beta-galactoside alpha-2,6-sialyltransferase 2 }\end{array}$




\section{References}

1. Prusiner, S.B. Novel proteinaceous infectious particles cause scrapie. Science 1982, 216, 136-144. [CrossRef] [PubMed]

2. Legname, G.; Baskakov, I.V.; Nguyen, H.O.B.; Riesner, D.; Cohen, F.E.; DeArmond, S.J.; Prusiner, S.B. Synthetic mammalian prions. Science 2004, 305, 673-676. [CrossRef] [PubMed]

3. Cohen, F.E.; Prusiner, S.B. Pathologic conformations of prion proteins. Annu. Rev. Biochem. 1998, 67, $793-819$. [CrossRef] [PubMed]

4. Baskakov, I.V.; Breydo, L. Converting the prion protein: What makes the protein infectious. Biochim. Biophys Acta. 2007, 1772, 692-703. [CrossRef] [PubMed]

5. Lu, Z.Y.; Baker, C.A.; Manuelidis, L. New Molecular Markers of Early and Progressive CJD Brain Infection. J. Cell Biochem. 2004, 93, 644-652. [CrossRef] [PubMed]

6. Baker, C.A.; Manuelidis, L. Unique inflammatory RNA profiles of microglia in Creutzfeldt-Jakob disease. Proc. Natl. Acad. Sci. USA 2003, 100, 675-679. [CrossRef] [PubMed]

7. Carroll, J.A.; Striebel, J.F.; Rangel, A.; Woods, T.; Phillips, K.; Peterson, K.E.; Race, B.; Chesebro, B. Prion Strain Differences in Accumulation of PrPSc on Neurons and Glia Are Associated with Similar Expression Profiles of Neuroinflammatory Genes: Comparison of Three Prion Strains. PLoS Pathog. 2016, 12, e1005551. [CrossRef]

8. Collinge, J.; Clarke, A.R. A General Model of Prion Strains and Their Pathogenicity. Science 2007, 318, 930-936. [CrossRef]

9. Kimberlin, R.H.; Cole, S.; Walker, C.A. Temporary and permanent modifications to a single strain of mouse scrapie on transmission to rats and hamsters. J. Gen. Virol. 1987, 68, 1875-1881. [CrossRef]

10. Kimberlin, R.H.; Walker, C.A.; Fraser, H. The genomic identity of different strains of mouse scrapie is expressed in hamsters and preserved on reisolation in mice. J. Gen. Virol. 1989, 70, 2017-2025. [CrossRef]

11. Bruce, M.E.; Dickinson, A.G. Biological evidence that the scrapie agent has an independent genome. J. Gen. Virol. 1987, 68, 79-89. [CrossRef] [PubMed]

12. Karapetyan, Y.E.; Saa, P.; Mahal, S.P.; Sferrazza, G.F.; Sherman, A.; Sales, N.; Weissmann, C.; Lasmezas, C.I. Prion strain discrimination based on rapid in vivo amplification and analysis by the cell panel assay. PLoS ONE 2009, 4, e5730. [CrossRef] [PubMed]

13. Bessen, R.A.; Marsh, R.F. Identification of two biologically distinct strains of transmissible mink encephalopathy in hamsters. J. Gen. Virol. 1992, 73, 329-334. [CrossRef] [PubMed]

14. Peretz, D.; Scott, M.; Groth, D.; Williamson, A.; Burton, D.; Cohen, F.E.; Prusiner, S.B. Strain-specified relative conformational stability of the scrapie prion protein. Protein Sci. 2001, 10, 854-863. [CrossRef]

15. Safar, J.; Wille, H.; Itri, V.; Groth, D.; Serban, H.; Torchia, M.; Cohen, F.E.; Prusiner, S.B. Eight prion strains have PrP Sc molecules with different conformations. Nat. Med. 1998, 4, 1157-1165. [CrossRef]

16. Ayers, J.L.; Schutt, C.R.; Shikiya, R.A.; Aguzzi, A.; Kincaid, A.E.; Bartz, J.C. The strain-encoded relationship between PrP replication, stability and processing in neurons is predictive of the incubation period of disease. PLOS Pathog. 2011, 7, e1001317. [CrossRef]

17. Gonzalez-Montalban, N.; Makarava, N.; Savtchenko, R.; Baskakov, I.V. Relationship between Conformational Stability and Amplification Efficiency of Prions. Biochemistry 2011, 50, 7933-7940. [CrossRef]

18. Klimova, N.; Makarava, N.; Baskakov, I.V. The diversity and relationship of prion protein self-replicating states. Virus Res. 2015, 207, 113-119. [CrossRef]

19. Caughey, B.; Raymond, G.J.; Bessen, R.A. Strain-dependent differences in b-sheet conformations of abnormal prion protein. J. Biol. Chem. 1998, 273, 32230-32235. [CrossRef]

20. Thomzig, A.; Spassov, S.; Friedrich, M.; Naumann, D.; Beekes, M. Discriminating Scrapie and Bovine Spongiform Encephalopathy Isolates by Infrared Spectroscopy of Pathological Prion Protein. J. Biol. Chem. 2004, 279, 33854. [CrossRef]

21. Spassov, S.; Beekes, M.; Naumann, D. Structural differences between TSEs strains investigated by FT-IR spectroscopy. Biochim. Biophys Acta 2006, 1760, 1138-1149. [CrossRef] [PubMed]

22. Tixador, P.; Herzog, L.; Reine, F.; Jaumain, E.; Chapuis, J.; Le Dur, A.; Laude, H.; Beringue, V. The physical relationship between infectivity and prion protein aggregates is strain-dependent. PLOS Pathog. 2010, 6, e1000859. [CrossRef] [PubMed] 
23. Morales, R.; Hu, P.P.; Duran-Aniotz, C.; Moda, F.; Diaz-Espinoza, R.; Chen, B.; Bravo-Alegria, J.; Makarava, N.; Baskakov, I.V.; Soto, C. Strain-dependent profile of misfolded prion protein aggregates. Sci. Rep. 2016, 6, 20526. [CrossRef] [PubMed]

24. Stahl, N.; Borchelt, D.R.; Hsiao, K.; Prusiner, S.B. Scrapie prion protein contains a phosphatidylinositol glycolipid. Cell 1987, 51, 229-240. [CrossRef]

25. Endo, T.; Groth, D.; Prusiner, S.B.; Kobata, A. Diversity of oligosaccharide structures linked to asparagines of the scrapie prion protein. Biochemistry 1989, 28, 8380-8388. [CrossRef]

26. Turk, E.; Teplow, D.B.; Hood, L.E.; Prusiner, S.B. Purification and properties of the cellular and scrapie hamster prion proteins. Eur. J. Biochem. 1988, 176, 21-30. [CrossRef]

27. Katorcha, E.; Makarava, N.; Savtchenko, R.; Baskakov, I.V. Sialylation of the prion protein glycans controls prion replication rate and glycoform ratio. Sci. Rep. 2015, 5, 16912. [CrossRef]

28. Stimson, E.; Hope, J.; Chong, A.; Burlingame, A.L. Site-specific characterization of the N-linked glycans of murine prion protein by high-performance liquid chromatography/electrospray mass spectrometry and exoglycosidase digestions. Biochemistry 1999, 38, 4885-4895. [CrossRef]

29. Katorcha, E.; Baskakov, I.V. Analyses of N-linked glycans of PrPSc revealed predominantly 2,6-linked sialic acid residues. FEBS J. 2017, 284, 3727-3738. [CrossRef] [PubMed]

30. Stahl, N.; Baldwin, M.A.; Teplow, D.B.; Hood, L.; Gibson, B.W.; Burlingame, A.L.; Prusiner, S.B. Structural studies of the scrapie prion protein using mass spectrometry and amino acid sequencing. Biochemistry 1993, 32, 1991-2002. [CrossRef]

31. Rudd, P.M.; Endo, T.; Colominas, C.; Groth, D.; Wheeler, S.F.; Harvey, D.J.; Wormald, M.R.; Serban, H.; Prusiner, S.B.; Kobata, A.; et al. Glycosylation differences between the normal and pathogenic prion protein isoforms. Proc. Natl. Acad. Sci. U S A 1999, 96, 13044-13049. [CrossRef] [PubMed]

32. Bolton, D.C.; Meyer, R.K.; Prusiner, S.B. Scrapie PrP 27-30 is a sialoglycoprotein. J. Virol. 1985, 53, 596-606. [CrossRef] [PubMed]

33. Baskakov, I.V.; Katorcha, E. Multifaceted role of sialylation in prion diseases. Front. Neurosci. 2016, 10, 358. [CrossRef] [PubMed]

34. Baskakov, I.V.; Katorcha, E.; Makarava, N. Prion Strain-Specific Structure and Pathology: A View from the Perspective of Glycobiology. Viruses 2018, 10, 723. [CrossRef]

35. Baskakov, I.V. Limited understanding of the functional diversity of N-linked glycans as a major gap of prion biology. Prion 2017, 11, 82-88. [CrossRef]

36. Kooyk, Y.; Rabinovich, G.A. Protein-glycan interactions in the control of innate and adaptive immune responses. Nat. Immunol. 2008, 9, 593-601. [CrossRef]

37. Varki, A.; Gagneux, P. Multifarious roles of sialic acid in immunity. Ann. New York Acad. Sci. 2012, 1253, 16-36. [CrossRef]

38. Linnartz-Gerlach, B.; Mathews, M.; Neumann, H. Sensing the neuronal glycocalyx by glial sialic acid binding immunoglobulin-like lectins. Neuroscience 2014, 275, 113. [CrossRef]

39. Linnartz-Gerlach, B.; Schuy, C.; Shahraz, A.; Tenner, A.J.; Neumann, H. Sialylation of neurites inhibits complement-mediated macrophage removal in a human macrophage-neuron Co-Culture System. Glia 2016, 64, 35-47. [CrossRef]

40. Srivastava, S.; Katorcha, E.; Makarava, N.; Barrett, J.P.; Loane, D.J.; Baskakov, I.V. Inflammatory response of microglia to prions is controlled by sialylation of $\mathrm{PrP}^{\mathrm{Sc}}$. Sci. Rep. 2018, 8, e11326. [CrossRef]

41. Varki, A. Sialic acids in human health and disease. Trends Mol. Med. 2008, 14, 351-360. [CrossRef] [PubMed]

42. Brown, G.C.; Neher, J.J. Microglial phagocytosis of live neurons. Nat. Rev. Neurosc. 2014, 15, $209-216$. [CrossRef] [PubMed]

43. Aminoff, D.; Bruegge, W.F.; Bell, W.C.; Sarpolis, K.; Williams, R. Role of sialic acid in survival of erythrocytes in the circulation: interaction of neuraminidase-treated and untreated erythrocytes with spleen and liver at the cellular level. Proc. Acad. Natl. Sci. U S A 1977, 74, 1521-1524. [CrossRef] [PubMed]

44. Jansen, A.J.G.; Josefsson, E.C.; Rumjantseva, V.; Liu, Q.P.; Falet, H.; Bergmeier, W.; Cifuni, S.; Sackstein, R.; von Andrian, U.H.; Wagner, D.D.; et al. Desialylation accelerates platelet clearance after refrigeration and initiates GPIba metalloproteinase-mediated cleavage in mice. Blood 2012, 119, 1263-1273. [CrossRef] [PubMed] 
45. Katorcha, E.; Makarava, N.; Savtchenko, R.; D'Azzo, A.; Baskakov, I.V. Sialylation of prion protein controls the rate of prion amplification, the cross-species barrier, the ratio of PrPSc glycoform and prion infectivity. PLOS Pathog. 2014, 10, e1004366. [CrossRef] [PubMed]

46. Srivastava, S.; Makarava, N.; Katorcha, E.; Savtchenko, R.; Brossmer, R.; Baskakov, I.V. Post-conversion sialylation of prions in lymphoid tissues. Proc. Acad. Natl. Sci. U S A 2015, 112, E6654-E6662. [CrossRef]

47. Katorcha, E.; Daus, M.L.; Gonzalez-Montalban, N.; Makarava, N.; Lasch, P.; Beekes, M.; Baskakov, I.V. Reversible off and on switching of prion infectivity via removing and reinstalling prion sialylation. Sci. Rep. 2016, 6, 33119. [CrossRef]

48. Srivastava, S.; Katorcha, E.; Daus, M.L.; Lasch, P.; Beekes, M.; Baskakov, I.V. Sialylation controls prion fate in vivo. J. Biol. Chem. 2017, 292, 2359-2368. [CrossRef]

49. Collinge, J. Prion strain mutation and selection. Science 2010, 328, 1111-1112. [CrossRef]

50. Piro, J.R.; Harris, B.T.; Nishina, K.; Soto, C.; Morales, R.; Rees, J.R.; Supattapone, S. Prion Protein Glycosylation Is Not Requiered for Strain-Specific Neurotropism. J. Virol. 2009, 83, 5321-5328. [CrossRef]

51. Katorcha, E.; Baskakov, I.V. Analysis of Covalent Modifications of Amyloidogenic Proteins Using Two-Dimensional Electrophoresis: Prion Protein and Its Sialylation. Methods Mol. Biol 2018, 1779, 241-255. [PubMed]

52. Zou, W.Q.; Capellari, S.; Parchi, P.; Sy, M.S.; Gambetti, P.; Chen, S.G. Identification of Novel Proteinase K-resistant C-terminal Fragments of PrP in Creutzfeldt-Jakob Disease. J. Biol. Chem. 2003, 278, 40429-40436. [CrossRef] [PubMed]

53. Monaco, S.; Fiorini, M.; Farinazzo, A.; Ferrari, S.; Gelati, M.; Piccardo, P.; Zanusso, G.; Ghetti, B. Allelic origin of protease-sensitive and protease-resistant prion protein isoforms in Gerstmann-Sträussler-Scheinker disease with the P102L mutation. PLoS One 2012, 7, e32382. [CrossRef]

54. Stahl, N.; Baldwin, M.A.; Hecker, R.; Pan, K.M.; Burlingame, A.L.; Prusiner, S.B. Glycosylinositol phospholipid anchors of the scrapie and cellular prion proteins contain sialic acid. Biochemistry 1992, 31, 5043-5053. [CrossRef]

55. Katorcha, E.; Srivastava, S.; Klimova, N.; Baskakov, I.V. Sialylation of GPI Anchors of Mammalian Prions is Regulated in a Host-, Tissue- and Cell-Specific Manner. J. Biol. Chem. 2016, 291, 17009-17019. [CrossRef] [PubMed]

56. Miyagi, T.; Yamaguchi, K. Mammalian sialidases: physiological and pathological roles in cellular functions. Glycobiology 2012, 22, 880-896. [CrossRef]

57. Audry, M.; Jeanneau, C.; Imberty, A.; Harduin-Lepers, A.; Delannoy, P.; Breton, C. Current trend in the structure-activity relationships of sialylatransferases. Glycobiology 2011, 21, 716-726. [CrossRef]

58. Katorcha, E.; Klimova, N.; Makarava, N.; Savtchenko, R.; Pan, X.; Annunziata, I.; Takahashi, K.; Miyagi, T.; Pshezhetsky, A.V.; d'Azzo, A.; et al. Knocking out of cellular neuraminidases Neu1, Neu3 or Neu4 does not affect sialylation status of the prion protein. PLOS ONE 2015, 10, e0143218.

59. Takashima, S. Characterization of Mouse Sialylatransferase Gene: their Evolution and Diversity. Biosci. Biotechnol. Biochem. 2008, 72, 1155-1167. [CrossRef]

60. Guillerme-Bosselut, F.; Forestier, L.; Jayat-Vignoles, C.; Vilotte, J.L.; Popa, I.; Portoukalian, J.; Dur, A.L.; Laude, H.; Julien, R.; Gallet, P.F. Glycosylation-related gene expression profiling in the brain and spleen of scrapie-affected mouse. Glycobiology 2009, 19, 879-889. [CrossRef]

61. Cancellotti, E.; Bradford, B.M.; Tuzi, N.L.; Hickey, R.D.; Brown, D.; Brown, K.L.; Barron, R.M.; Kisielewski, D.; Piccardo, P.; Manson, J.C. Glycosylation of PrPC determines timing of neuroinvasion and targeting in the brain following transmissible spongiform encephalopathy infection by a peripheral route. J. Virol. 2010, 84, 3464-3475. [CrossRef]

62. Lehoux, S.; Groux-Degroote, S.; Cazet, A.; Dhaenens, C.-M.; Maurage, C.-A.; Caillet-Boudin, M.-L.; Delannoy, P.; Krzewinski-Recchi, M.-A. Transcriptional regulation of the human ST6GAL2 gene in cerebral cortex and neuronal cells. Glycoconj. J. 2010, 27, 99-114. [CrossRef] [PubMed]

63. Takashima, S.; Tsuji, S.; Tsujimoto, M. Comparison of the enzymatic properties of mouse beta-galactoside alpha2,6-sialyltransferases, ST6Gal I and II. J.Biochem. 2003, 134, 287-296. [CrossRef] [PubMed]

64. Takashima, S.; Truji, S.; Tsujimoto, M. Characterization of the second type of human beta-galactoside alpha 2,6-sialyltransferase (ST6Gal II), which sialylates Galbeta 1,4GlcNAc structures on oligosaccharides preferentially. Genomic analysis of human sialyltransferase genes. J. Biol. Chem. 2002, 277, 45719-45728. [CrossRef] [PubMed] 
65. Cobb, B.A. The history of IgG glycosylation and where we are now. Glycobiology 2019. [CrossRef] [PubMed]

66. Makarava, N.; Chang, J.C.-Y.; Kushwaha, R.; Baskakov, I.V. Region-Specific Response of Astrocytes to Prion Infection. Front. Neurosci. 2019, 13, 1048. [CrossRef]

67. Bradford, B.M.; Wijaya, C.A.W.; Mabbott, N.A. Discrimination of Prion Strain Targeting in the Central Nervous System via Reactive Astrocyte Heterogeneity in CD44 Expression. Front. Cell. Neurosci. 2019, 13, 411. [CrossRef]

68. Mathys, H.; Adaikkan, C.; Gao, F.; Young, J.Z.; Manet, E.; Hemberg, M.; De Jager, P.L.; Ransohoff, R.M.; Regev, A.; Tsai, L.-H. Temporal Tracking of Microglia Activation in Neurodegeneration at Single-Cell Resolution. Cell Reports 2017, 21, 366-380. [CrossRef]

69. Grabert, K.; Michoel, T.; Karavolos, M.H.; Clohisey, S.; Baillie, J.K.; Stevens, M.P.; Freeman, T.C.; Summers, K.M.; McColl, B.W. Microglial brain region-dependent diversity and selective regional sensitivities to aging. Nat. Neurosci. 2016, 19, 504. [CrossRef] [PubMed]

70. Soreq, L.; Consortium, U.B.E.; Consortium, N.A.B.E.; Rose, J.; Soreq, E.; Hardy, J.; Trabzuni, D.; Cookson, M.R.; Smith, C.; Ryten, M.; et al. Major Shifts in Glial Regional Identity Are a Transcriptional Hallmark of Human Brain Aging. Cell Rep. 2017, 18, 557-570. [CrossRef] [PubMed]

71. Clarke, L.E.; Liddelow, S.A.; Chakraborty, C.; Munich, A.E.; Heiman, M.; Barres, B.A. Normal aging induces A1-like astrocyte reactivity. Proc. Natl. Acad. Sci. USA 2018, 115, E1896-E1905. [CrossRef] [PubMed]

72. Boisvert, M.M.; Erikson, G.A.; Shokhirev, M.N.; Allen, N.J. The Aging Astrocyte Transcriptome from Multiple Regions of the Mouse Brain. Cell Rep. 2018, 22, 269-285. [CrossRef] [PubMed]

73. Zeisel, A.; Hochgerner, H.; Lonnerberg, P.; Johnsson, A.; Memic, F.; van der Zwan, J.; Harig, M.; Braun, E.; Borm, L.E.; La Manno, G.; et al. Molecular Architecture of the Mouse Nervous System. Cell 2018, 174, 999-1014. [CrossRef] [PubMed]

74. Makarava, N.; Chang, J.C.-Y.; Molesworth, K.; Baskakov, I.V. Loss of region-specific glial homeostatic signature in prion diseases. BioRxiv 2019, 823732.

75. Sandberg, M.K.; Al-Doujaily, H.; Sharps, B.; De Oliveira, M.W.; Schmidt, C.; Richard-Londt, A.; Lyall, S.; Linehan, J.M.; Brandner, S.; Wadsworth, J.D.; et al. Prion neuropathology follows the accumulation of alternate prion protein isoforms after infective titre has peaked. Nat. Commun. 2014, 5, e4347. [CrossRef]

(C) 2020 by the authors. Licensee MDPI, Basel, Switzerland. This article is an open access article distributed under the terms and conditions of the Creative Commons Attribution (CC BY) license (http://creativecommons.org/licenses/by/4.0/). 